\title{
Marketing, \\ estrategia y género. \\ La fijación de límites en \\ el uso de la imagen \\ de la mujer en publicidad
}

Marketing, Strategy and Gender.

Setting limits on the use of the image of Women in Advertising

Dra. Emma Torres-Romay

Profesora titular. Facultad de Ciencias Sociales y de la

Comunicación, Universidad de Vigo.

emmatr@uvigo.es

Dra. Silvia García-Mirón

Profesora contratada. Facultad de Ciencias y de la Sociales y de la Comunicación, Universidad de Vigo

silviamiron@uvigo.es
Torres-Romay, E. y García-Mirón, S. (2020)

Marketing, estrategia y género. La fijación de límites en el uso de la imagen de la mujer en publicidad

Revista Internacional de Investigación en Comunicación aDResearch ESIC. No 22 Vol 22

Monográfico especial, marzo 2020 · Págs. 10 a 33

https://doi.org/10.7263/adresic-022-01 
RESUMEN

\author{
Clasificación JEL: \\ M31, M37, J16 \\ Palabras clave: \\ Marketing, \\ estrategia, \\ género, \\ mujer, \\ publicidad
}

Objetivo del estudio: El propósito de este artículo es realizar un análisis cualitativo de la situación actual del uso de la imagen de la mujer en la publicidad, intentando establecer una clasificación de esos usos e identificando la gestión del género desde la perspectiva del marketing.

Diseño/metodología/enfoque: Para lograr nuestro objetivo se ha realizado un seguimiento en torno a una base de datos de elaboración propia, creada en el año 2008 y que se mantiene en crecimiento en la actualidad (para esta y otras investigaciones). En un universo compuesto por más de 700 campañas en el periodo entre 2008 y 2019 hemos recogido los casos que han suscitado algún tipo de polémica por el incorrecto uso de la imagen de la mujer, cruzando los mismos con las denuncias y sentencias dictadas en torno a sexismo en publicidad.

Resultados: Todo ello ha permitido establecer, mediante ese minucioso estudio de casos, una categorización de los principales problemas existentes en cuanto a la imagen de la mujer en la comunicación comercial. Además de lo anterior, hemos podido determinar las vías actuales que las principales marcas están empleando para contrarrestar estos problemas.

Limitaciones/implicaciones: Los resultados de este trabajo tienen implicaciones sociales de gran calado ya que supone poner sobre la mesa problemas de sexismo y maltrato de la imagen de la mujer que estaban pasando desapercibidos o incluso estaban asumidos.

Originalidad/contribución: Se trata de una aportación de gran interés ya que, en los últimos años se han reducido notablemente los estudios a este respecto y, si bien la perspectiva cuantitativa parece estar cubierta por algunas instituciones, no se contemplan valoraciones cualitativas sobre qué tipo de mensajes se están divulgando y, sobre todo, si se está evolucionando y mejorando en este aspecto.

\section{ABSTRACT}

JEL Classification:

M31, M37, J16

Key words:

Marketing,

strategy,

gender,

woman,

advertising
Purpose: The purpose of this article is to carry out a qualitative analysis of the current situation of the use of the image of women in advertising, trying to establish a classification of these uses and identifying gender management from the perspective of marketing.

Design / Methodology / Approach: To achieve our objective, we have monitored a database of own-made advertising, created in 2008 and which is still growing today (for this and other research). In a universe composed of more than 700 campaigns and delimiting the period between 2008 and 2019, we have collected cases that have provoked some kind of controversy due to the incorrect use of the image of women, cross-referencing with the complaints and sentences handed down around sexism in advertising in our country was carried out.

Results: This has made it possible to establish, through this detailed case study, a categorization of the main existing problems regarding the image of women in commercial communication. In addition to the above, we have been able to identify the current avenues that the major brands are employing to counter these problems.

Limitations / Implications: The results of this work have far-reaching social implications, since it involves raising problems of sexism and mistreatment of the image of women that were going unnoticed or even assumed.

Originality / Contribution: This is a contribution of great interest since, in recent years, studies on this subject have been significantly reduced and, although the quantitative perspective seems to be covered by some institutions, no qualitative assessments are contemplated as to what kind of messages are being disseminated and, above all, whether they are evolving and improving in this regard. 


\section{Introducción}

El sector de la publicidad ha protagonizado en numerosas ocasiones polémicas en torno al (mal) uso que realiza de la imagen de la mujer. Ese maltrato del rol femenino fue, a finales del siglo pasado y en el actual, objeto de estudio de numerosos trabajos e investigaciones tanto en lo relativo a los medios de comunicación en general (Balaguer, 1985) como a la publicidad en particular (García y García, 2004). Se trataba de intentar identificar los elementos que condicionaban ese trato desigual (Arconada y Lomas, 1999) y catalogar los estereotipos que deben evitarse (Peña-Marín y Fabretti, 1990). Sin embargo, en la última década la preocupación, que se mantiene latente, no ha generado tanta atención académica. La perspectiva actual nos permite realizar una valoración de esa relación entre mujer y publicidad (Montero, 2011) e incluso identificar avances o mejoras (Berganza y Del Hoyo, 2011).

Existe, por tanto, una amplia bibliografía relativa al tema, pero en la misma se advierte una característica particular en lo referido a las metodologías aplicadas. Abundan los trabajos que aplican modelos de análisis a una muestra determinada de piezas publicitarias (Del Moral, 2000) y aquellos que, mediante revisión bibliográfica, identifican tendencias y aportan propuestas de investigación (Santiso, 2011), teniendo también una importante presencia los estudios de la legislación existente en torno a este fenómeno (Balaguer, 2008) pero no son tan comunes los análisis de casos específicos. En los últimos años debemos destacar como se han concretado los contenidos hablando específicamente de roles y estereotipos de género (Ruiz Vidales y Muñiz, 2017) y mostrando especial interés por el uso del cuerpo femenino (Vega Saldaña, Barredo Ibáñez y Merchán Clavellino, 2019), tema que cuenta con amplias referencias en el ámbito académico internacional (Grau y Zotos, 2016).

Nuestro objeto de estudio se centra, por tanto, en la representación de la mujer en publicidad por lo que el método de análisis de contenido (Craig, 1992) resultará crucial al identificar, no sólo cuestiones relativas a la imagen, si no a los conceptos y roles adjudicados (Eisend, Dens, y De Pelsmacker, 2019). Nos centramos en la publicidad impresa (periódicos y revistas) y la audiovisual (televisión) sin entrar en el análisis de los medios digitales. Esta delimitación se establece por el hecho de que la base de datos creada se centra en medios más estables y menos cambiantes, características que cumplen los impresos y televisión e incluso debemos tener en cuenta el hecho de que el análisis referido a los medios digitales debería desarrollarse mediante otra metodología.

\section{Metodología}

Teniendo en cuenta todo lo anterior, en este trabajo nos planteamos aplicar una metodología de estudio de casos para valorar los principales problemas existentes en el momento actual en lo relativo a la representación de la mujer en la publicidad. Para ello nos servimos del material recopilado desde el año 2008 dentro de la actividad desarrollada en la Facultad de Ciencias Sociales y de la Comunicación de la Universidad de Vigo, donde se mantiene una recopilación permanente de campañas que da lugar a una base de datos viva y que sigue creciendo en la actualidad. La base de datos fue puesta en marcha inicialmente para identificar cambios de tendencia como consecuencia de la crisis económica, pero que también ha permitido recoger casos de sexismo en la publicidad. 
Para poder delimitar más concretamente la muestra, hemos cruzado los casos recogidos entre 2008 y 2019 en la base de datos con las denuncias ante distintos organismos así como las sentencias judiciales, dando como resultado una selección de 32 campañas que son sometidas a un proceso de análisis de contenido. Se trata, por tanto, de una propuesta exclusivamente cualitativa ya que, sin duda, la parte cuantificable de esta problemática está suficientemente cubierta por organismos como el Observatorio de la Imagen de la Mujer o la Asociación Autocontrol, que publican informes anuales a este respecto.

Contando con una muestra suficiente de casos que, cuando menos, plantean dudas por correcto o incorrecto uso de la imagen de la mujer, proponemos abordar su análisis realizando una breve aproximación normativa a este asunto, para posteriormente evaluar las tendencias existentes en lo relativo a la gestión estratégica del género desde el punto de vista del marketing para, finalmente, sintetizar los parámetros actuales de la relación entre publicidad y mujer. No realizamos, por tanto, una valoración concreta y pormenorizada de los casos si no que el estudio de estos nos ha permitido extrapolar las ideas que a continuación se relacionan. Ilustraremos cada una de ellas con los ejemplos correspondientes, sintetizando las ideas finales en el apartado de conclusiones del artículo.

Todo esto se concreta en un objetivo claro: realizar un análisis cualitativo de la situación actual del uso de la imagen de la mujer en la publicidad, intentando establecer una clasificación de esos usos e identificando la gestión del género desde la perspectiva del marketing y, como consecuencia, cuál es la representación actual de la mujer en la publicidad. Nuestro fin es llamar la atención sobre los cambios producidos al respecto de tal forma que se ha pasado de el sexismo claro e identificado a mensajes más sutiles e inocentes.

\section{Enfoque}

\subsection{Los límites de la publicidad en relación a la mujer}

\subsubsection{Legislación aplicable}

A pesar de la evolución que la comunicación comercial en general y la publicidad en particular ha desarrollado en los últimos años, la legislación en torno a su funcionamiento lleva décadas sin experimentar cambios. A día de hoy los límites legales de la publicidad en España están marcados por la Ley 34, General de publicidad, del 11 de noviembre de 1988 que sirvió para derogar el Estatuto de la Publicidad del año 1964. Dicha Ley sufrió revisiones relativas a la adaptación a otras normativas como por ejemplo, la Ley 29/2009, de 30 de diciembre, por la que se modifica el régimen legal de la competencia desleal y de la publicidad para la mejora de la protección de los consumidores y usuarios. También se han recogido regulaciones específicas en lo relativo a cuestiones sanitarias, como el consumo del tabaco* o medicamentos (Perelló, Muela y Hormigos, 2016) pero no se contemplan los cambios en lo relativo a la legislación en torno a la protección de la mujer en el contenido de los mensajes.

Sea como sea, el espíritu de la Ley no ha cambiado y en lo relativo a la publicidad ilícita (art. 3) incluye que es «aquella que atente contra la dignidad o vulnere los derechos reconocidos en la Constitución, especialmente en lo referido a la infancia y la mujer». Esto supone que la publicidad tiene límites establecidos y parte de la existencia de sujetos especialmente protegibles. El problema radica, en este punto, en la aplicación o control en lo relativo a esos límites, hecho que ya ha sido destacado estudios académicos, tanto en lo

\footnotetext{
* Ley 42/2010, de 30 de diciembre, por la que se modifica la Ley 28/2005, de 26 de diciembre, de medidas sanitarias frente al tabaquismo y reguladora de la venta, el suministro, el consumo y la publicidad de los productos del tabaco.
} 
referido a los menores (Martínez y Nicolás, 2019), como en el caso de las mujeres (Santiso, 2001), si bien en este último caso la perspectiva legislativa parece haber perdido interés en los últimos años.

Debemos tener en cuenta que la actual legislación en torno a la violencia de género incluye varios aspectos relativos a la publicidad (NavarroBeltrá y Martí Llaguno, 2012). Así la Ley Orgánica de Medidas de Protección Integral contra la Violencia de Género, que se promulga en España en el año 2004, regula y penaliza la discriminación por sexo en la comunicación comercial, incluyendo un capítulo específico sobre «el ámbito de la publicidad y de los medios de comunicación». Sin embargo, en su artículo 10 recupera la Ley General de Publicidad de 1988 indicando que se considerará ilícita la publicidad que «utilice la imagen de la publicidad con carácter vejatorio o discriminatorio».

Según indican Navarro-Beltrá y Martí (2012: 249) la definición de publicidad sexista "ha sido ligeramente modificada por la creación de la Ley por la que se Modifica el Régimen Legal de la Competencia Desleal y de la Publicidad Para la Mejora de la Protección de Consumidores y usuarios (2009). Específicamente, esta normativa introduce el artículo 14 de la Constitución y añade la palabra «discriminatoria» junto al vocablo «vejatoria»" pero se incide en que no se modifican los supuestos básicos contemplado en normativas anteriores por lo que se considera sexista el «uso del cuerpo de la mujer o partes de éste como simple objeto sin vinculación con el producto promocionado y la utilización de la imagen de la mujer vinculada a comportamientos estereotipados capaces de coadyuvar a generar violencia de género» (Navarro-Beltrá y Martí, 2012: 249).

Así, en la reciente historia de la publicidad, hemos sido testigos de polémicas y debates en torno a ciertas campañas publicitarias que so- brepasaron estos límites, si bien estas no sufrían consecuencias legales por dicho comportamiento más que en casos muy concretos. Como ejemplo la sentencia del Juzgado de lo Mercantil número 2 de Málaga declarando ilícita y desleal la publicidad de Ryanair en la que aparecían azafatas en bikini que había sido denunciada en diciembre de 2012 por la Asociación de Consumidores y Usuarios Adecua. La sentencia condenaba a la compañía aérea al cese de la campaña y a la publicación del fallo en dos periódicos de difusión nacional. La jueza encargada del caso aplicó el referido artículo 3 de la Ley General de Publicidad (Imagen 1).

Sin embargo, en la mayor parte de los casos no llega a producirse la intervención de la justicia. La presión y la desaprobación de los propios consumidores, conseguían la reprobación social y el correspondiente cese del material publicitario

\section{Imagen 1 - Campaña de Ryanair (2012)}

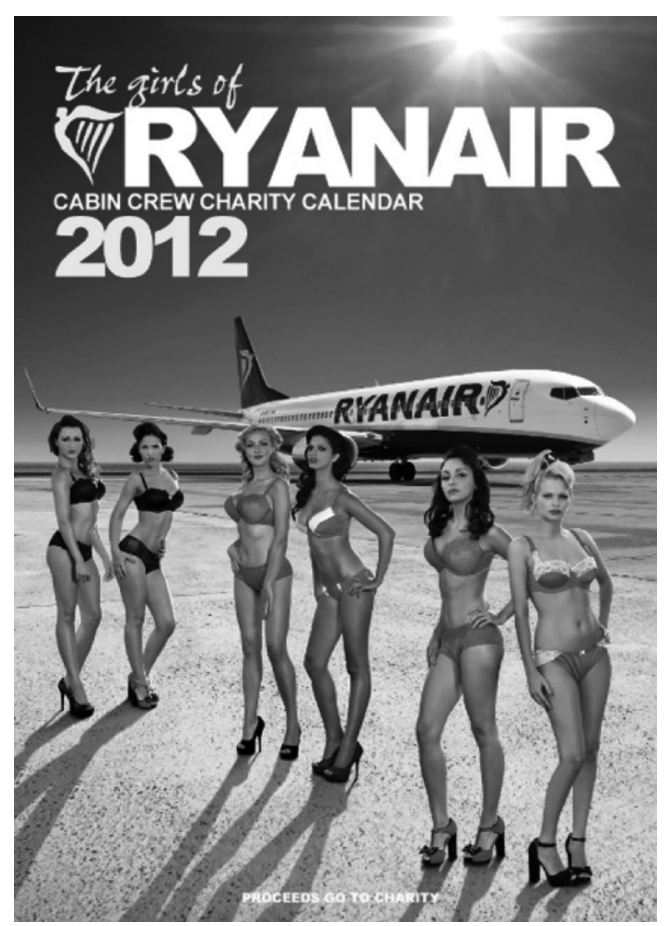




\section{Imagen 2 • Campaña de Dolce \& Gabbana (2008)}

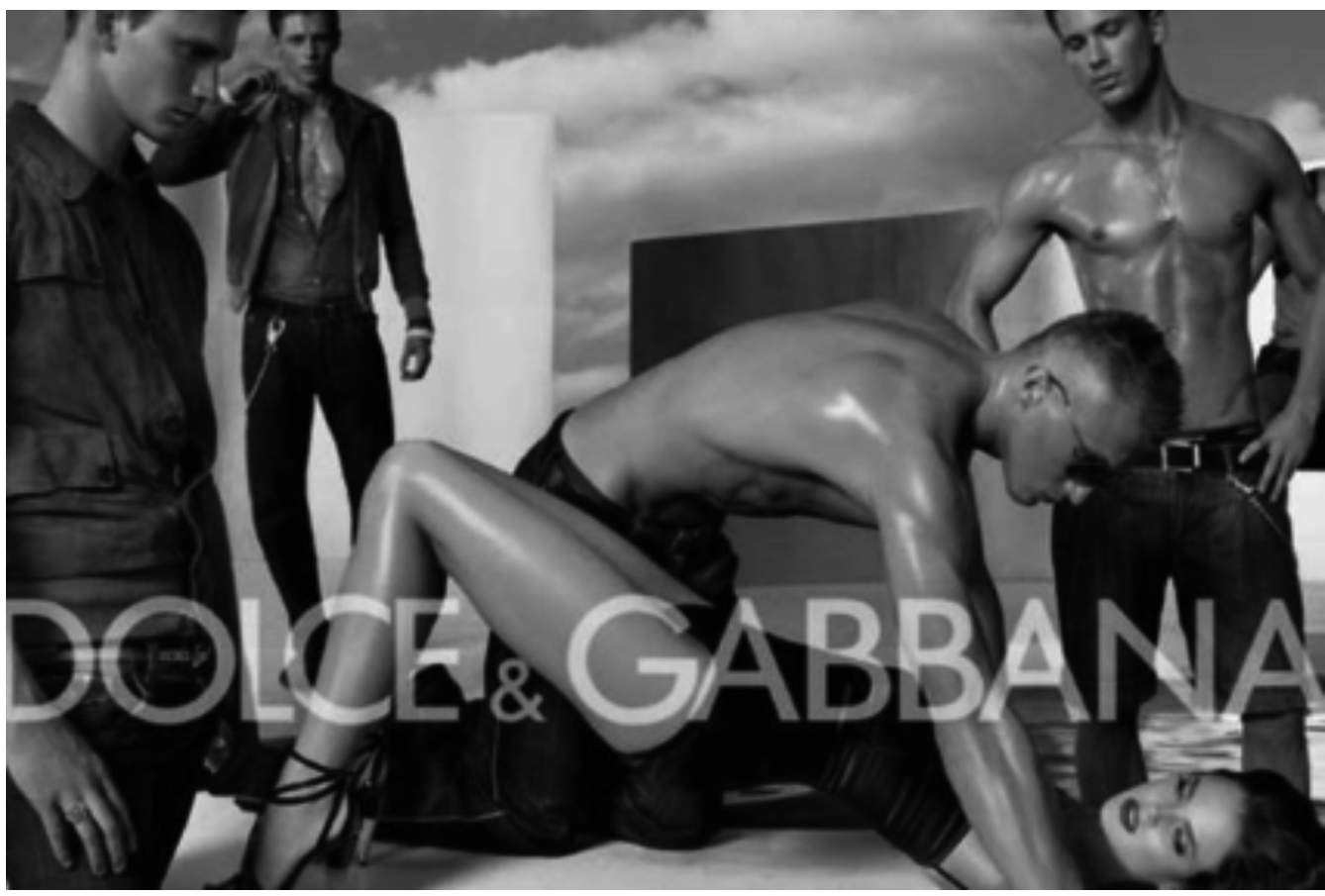

que resultaba inadecuado. Uno de los casos más recordados es la campaña de Dolce \& Gabbana de 2008, donde un hombre sujetaba por las muñecas a una mujer tumbada en el suelo mientras otros cuatro contemplaban la escena (Imagen 2). Amnistía Internacional consideró la campaña como «una apología de la violencia hacia la mujer» y el anuncio fue retirado.

\subsubsection{La autorregulación}

Quizá una de las dudas que surgen en este punto es cómo se aplica la legislación actual. A este respecto debemos destacar la existencia de cierta tradición en lo relativo al modelo de autorregulación en nuestro país. Sin embargo, también debemos volver a hacer alusión de nuevo a la Ley Orgánica 1/2004, de 28 de diciembre, de Medidas de Protección Integral contra la Violencia de Género que en el artículo 12 del Capítulo II establece los titulares de la acción de cesación y rectificación en el caso de publicidad ilícita indicando que: «la Delegación Especial del Gobierno contra la Violencia de la Mujer, el Instituto de la Mujer y órgano equivalente en cada Comunidad Autónoma, el Ministerio Fiscal y las Asociaciones que tengan como objetivo único la defensa de los intereses de la mujer estarán legitimados para ejercer ante los Tribunales la acción de cesación de publicidad ilícita por utilizar en forma vejatoria la imagen de la mujer en los términos de la Ley 34/1988 (...)».

Esto supone una amplia variedad de posibilidades en el ejercicio de la reclamación ante los tribunales y, sin duda, se confía en la existencia de entidades sociales o empresariales que ya estaban ejerciendo esa función desde antes de la aprobación de la ley en nuestro país. Así, la sentencias existentes en lo relativo a publicidad 
ilícita o publicidad sexista son fruto, mayoritariamente, de denuncias realizadas por colectivos sociales. Tal es el caso de la sentencia dictada en Barcelona contra una campaña de productos capilares (Imagen 3) que condenaba a la empresa a publicar el fallo en la prensa tras dictaminar que se trataba de publicidad sexista y que respondía a una demanda impulsada por la Asociación de Usuarios de la Comunicación por vulneración de derechos constitucionales (no se hace alusión a la Ley General de Publicidad ni a la Legislación de 2004 sobre Violencia de Género). Sin embargo, precisamente en 2017, tan sólo seis denuncias llegaron a los tribunales, quedando claro que la presión popular es suficiente para que las campañas de este tipo desaparezcan.

Esta capacidad de presión social ha sido aprovechada para la existencia de una autorregulación operativa. Desde el año 1995 la Asociación para la Autorregulación de la Comunicación Comercial (Autocontrol) ha puesto en marcha un sistema

\section{Imagen 3 - Campaña de productos capilares (2017)}

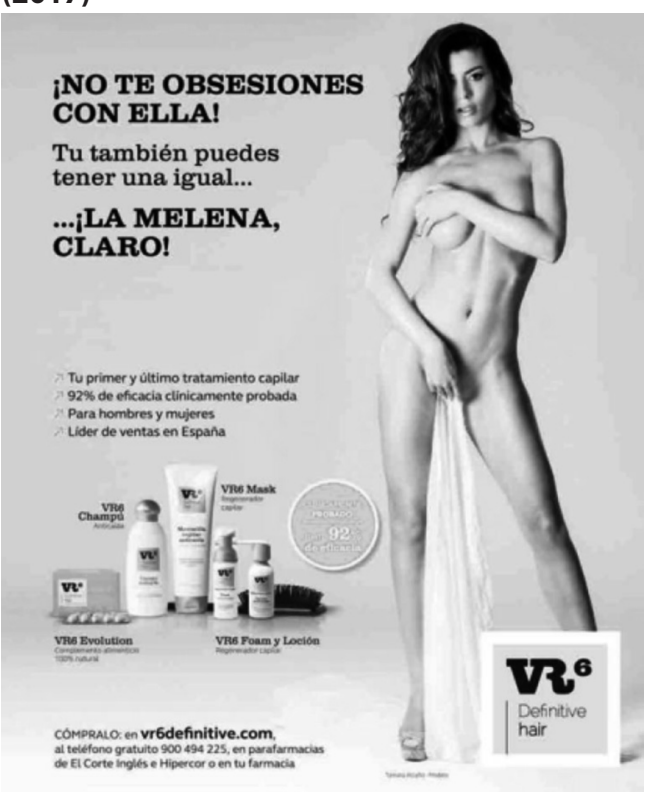

de control para poder garantizar la confianza y credibilidad de la publicidad sin llegar a la vía judicial. En el año 2014 este organismo realizó revisiones previas de 24.810 campañas y atendió reclamaciones referidas a 289 casos. En 2018 ese número ascendió a 47.642 consultas de las cuales 36.385 fueron consultas voluntarias sobre anuncios antes de su difusión. Quizá este hecho es el que ha permitido que el Jurado de la Publicidad sólo tuviera que hacer frente a 185 casos, correspondientes a un total de 207 reclamaciones sobre campañas publicitarias (Autocontrol, 2019). Todo ello sitúa España como el segundo país de la Unión Europea en el que más campañas publicitarias se someten anualmente a control previo voluntario.

A este respecto, el propio código de conducta de Autocontrol define (artículo 10) la publicidad discriminatoria, estableciendo que: «la publicidad no sugerirá circunstancias de discriminación ya sea por razón de raza, nacionalidad, religión, sexo u orientación sexual, ni atentará contra la dignidad de la persona. En particular se evitarán aquellos anuncios que puedan resultar vejatorios o discriminatorios para la mujer». Una vez más la mujer aparece como un sujeto especialmente protegible y esto supone una categoría específica en los supuestos de publicidad que Autocontrol se encarga de limitar.

Entre los casos con mayor repercusión del periodo estudiado es el de la campaña de la marca de ropa Desigual. En 2014 presentó una campaña de continuación de su línea «la vida es chula» en la que una mujer pinchaba un preservativo bajo la máxima de «tú decides». La plataforma Change. org recopiló 606 firmas que solicitaban la intervención de Autocontrol. Sin embargo la marca Desigual no era miembro de esta asociación por lo que, aunque Autocontrol realizó un informe sobre el caso, no existía compromiso para que la marca 
aceptara un dictamen sobre el mismo. A pesar de ello la empresa cedió realizando una modificación del spot (de hecho el vídeo ya no está disponible en el canal de Youtube de la marca).

\subsubsection{Control institucional}

Además de la legislación existente y de la autorregulación que el propio sector ha fomentado, existe en nuestro país cierto control institucional en lo referido específicamente al papel de la mujer en la publicidad. Después de varios cambios estructurales, en el momento actual (diciembre de 2019) el Ministerio de la Presidencia, Relaciones con las Cortes e Igualdad incluye con el Instituto de la Mujer y para la igualdad de Oportunidades que, a su vez, cuenta con diversos observatorios que trabajan en distintas áreas de mejora. Entre ellos podemos destacar el Observatorio de la Imagen de las Mujeres (OIM), heredero del Observatorio de la Publicidad Sexista creado en 1994 para «dar cumplimiento de los compromisos legales, tanto europeos como nacionales, de fomentar una imagen equilibrada y no estereotipada de las mujeres»"*. Al igual que sucedía en el anterior Observatorio de la Publicidad Sexista, este organismo permite la presentación de quejas sobre contenidos publicitarios o de los medios de comunicación que se consideren sexistas o incluyan imágenes estereotipadas de las mujeres.

De esta forma, si tomamos referencia del último informe, relativo al año 2018, el Observatorio recogió un total de 945 quejas de las cuales el $52,3 \%$ se referían al sector de la publicidad, el $25,4 \%$ al sector de medios e internet y el $22,3 \%$ a otros sectores y actividades. Esto supone un $8 \%$ menos que en el año anterior. En contra de lo recogido en la Ley de Violencia de Machista, la

\footnotetext{
** Página web del Instituto de la Mujer para la lgualdad de oportunidades: http://www.inmujer.gob.es/observatorios/observlmg/home.htm
}

\section{Imagen 4 • Campaña asociación nuestros hijos (2018)}

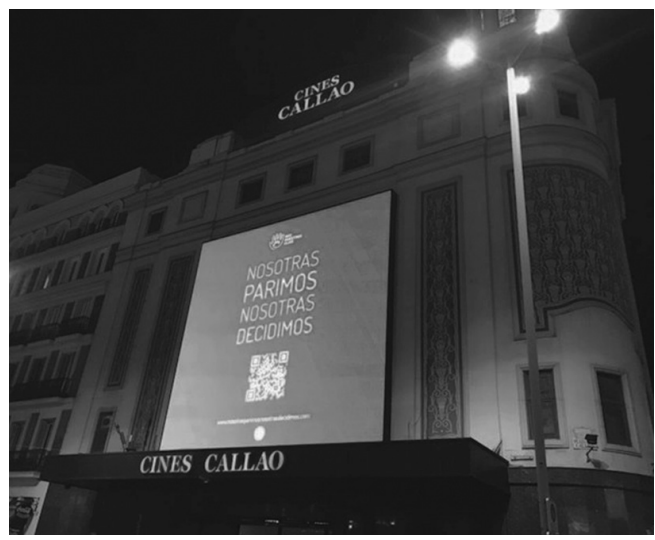

mayoría aplastante de las quejas (92,5\%) proceden de particulares (7,5\% de colectivos).

Desde un punto de vista más cualitativo, relativo al contenido de las quejas, el mayor número fue acumulado por la Asociación Nuestros Hijos (46 quejas) con una serie de pantallas y carteles en Madrid y Barcelona con el lema «Nosotros parimos, nosotras decidimos». Este caso sólo confirma una tendencia iniciada años atrás donde las principales quejas eran por el uso inadecuado de la imagen o cuerpo de la mujer (aunque sigan presentes) si no que parece que la presión social se concentra en los estereotipos, entendidos en sentido amplio (Ellemers, 2018). En 2017 la campaña que acumulaba más quejas era la de Calvo, con un spot de televisión donde se emplea el rol negativo de «suegra» además de «favorecer una visión negativa de las personas mayores y obesas». Tenemos que remontarnos hasta 2008 para encontrarnos con una campaña en la que el cuerpo femenino como reclamo sea el principal objeto de queja (campaña del abono para cítricos «Compo»).

Tampoco podemos pasar por alto el dato relativo al tipo de anunciante que es denunciado ya que, sorprendentemente, las administraciones públicas son uno de los sectores que recibe 
quejas en el Observatorio (en 2018 el 4,26 \% de las quejas). De hecho, una de las campañas que acumula el mayor número de quejas es la de la conmemoración del 300 aniversario de la Real Academia de la Lengua en 2013. La pieza fue denunciada por varias asociaciones de mujeres que la consideraron «sexista y discriminatorio» ya que, aprovechando el lema de la institución «Limpia, fija y da esplendor» se parodiaba un anuncio de detergente. Según las quejas presentadas, se presentaba a la mujer como responsable de las tareas de limpieza de la casa, lo que reproducía los estereotipos que fomentan la desigualdad (Observatorio, 2013).

Entre las denuncias presentadas encontramos una relativa a la campaña del propio Ministerio de Sanidad, Servicios Sociales e Igualdad denominada «Menores sin alcohol» en 2017 (Imagen 5). Tal y como se describe en el informe del Observatorio:

\section{Imagen 5 - Campaña Ministerio (2017)}

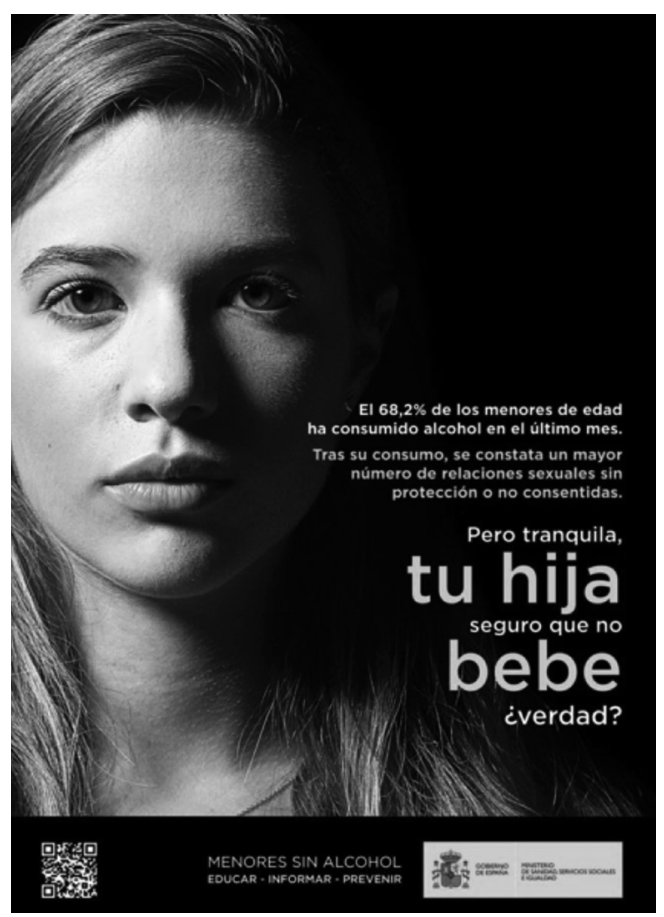

"la campaña muestra la imagen de una joven y, junto con unos datos sobre consumo de alcohol por menores, se inserta el siguiente texto: «Tras su consumo, se constata un mayor número de relaciones sexuales sin protección o no consentidas». El mensaje responsabiliza a las mujeres de la posible violencia sexual que pudieran sufrir por estar bajo los efectos del alcohol y puede interpretarse como una justificación de las agresiones" (Observatorio, 2017).

\subsubsection{Posibilidades de la publicidad}

Desde otro punto de vista, todo esto supone la existencia de una conciencia clara en torno a las consecuencias sociales que tiene la publicidad. Tanto es así que ya en 2000 la Asamblea de Naciones Unidas indicaban que «la revolución en la marcha de las comunicaciones mundiales y la introducción de las nuevas tecnologías de la

\section{Imagen 6 - Campaña Ministerio Igualdad (2009)}

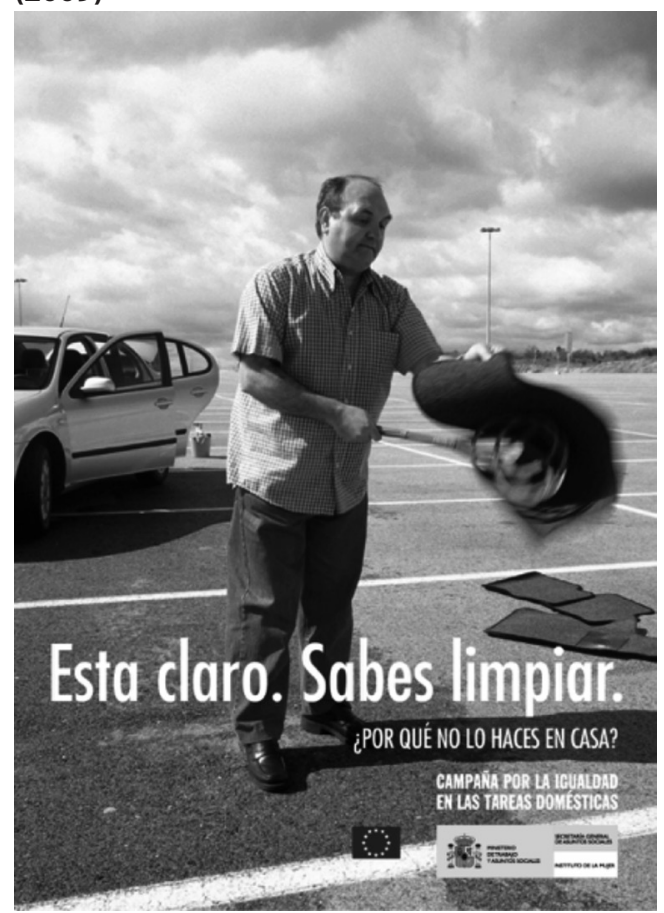


información hacen que en estos momentos los medios de comunicación puedan realizar una contribución histórica al adelanto de la mujer» (Naciones Unidas, 2000). Los límites de la publicidad parecen ser identificados socialmente y la mayor parte de las denuncias presentadas acaban en algún tipo de acción (recomendaciones o retiradas) por lo que todo apunta a que se comprende cómo debe representarse a la mujer.

De esta forma identificamos una potencial contribución de la publicidad a la mejora del papel de la mujer propiciada por dos factores. En primer lugar la publicidad sigue siendo un contenido fundamental de los medios de comunicación y, en segundo lugar, las representaciones y roles representados en los distintos contenidos publicitarios consiguen un reflejo directo en el contexto social y no sólo en lo relativo al consumo (Sahui, Canul y Vargas, 2015), sino en la propia configuración del imaginario colectivo (Ibarra, 2001). El auge de la publicidad digital y en redes sociales tan sólo ha consolidado esta situación.

Sea como sea, existe una clara potencialidad en lo relativo al uso de los medios de comunicación y, por extensión, de la publicidad, para la mejora de la situación social de la mujer. De esta forma, el Consejo de la Unión Europea invitaba, en 1995, a los estados miembros a desarrollar programas innovadores que ofrecieran una imagen realista de la mujer en la sociedad: «considerando que la publicidad y los medios de comunicación podrían contribuir el cambio de actitudes en la sociedad, reflejando la particular diversidad de funciones tanto de las mujeres como de los hombre en la vida pública y privada» (Diario Oficial de las Comunidades Europeas, 1995).

Las instituciones públicas españolas recogieron el guante en lo relativo al uso de la publicidad para la concienciación sobre la igualdad. Dentro de las campañas de sensibilización del Instituto de la Mujer y para la igualdad de oportunidades, dependiente del Ministerio de Asuntos Sociales, se alternaron campañas contra la violencia de género con las específicamente referidas al fomento de la igualdad, como la de 2003 relativa al reparto de las tareas domésticas ( EEstá claro, sabes limpiar», Imagen 6) que supuso un hito fundamental en ese momento. Desde el ámbito privado en 2008 «Punto Matic» protagonizó un caso positivo. Se trata de la campaña «Ellos también pueden» que indicaba «Caballeros: una vez un hombre puso la lavadora y no murió» iniciando así un camino importante en la representación del papel masculino en el hogar (Imagen 7).

En este punto, debemos indicar que el parón de las campañas de sensibilización en 2009 (tal y como se recoge en la documentación del propio Ministerio). De hecho, en los últimos años los esfuerzos públicos se han concentrado en la lucha contra la violencia machista, como prioridad frente a las campañas que manifestaban la

\section{Imagen 7 · Campaña Punto Matic (2008)}

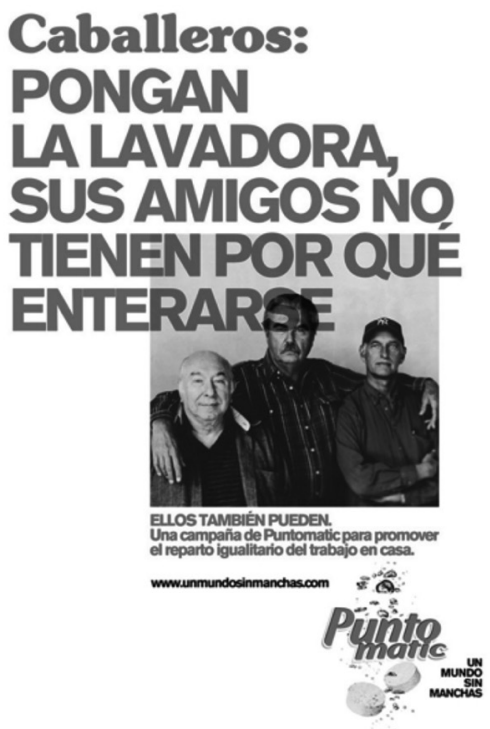


necesidad de igualdad o de ruptura de roles que se habían iniciado en la etapa anterior. Además las competencias en sensibilización en este aspecto corresponden a las comunidades autónomas y, desde la aprobación del Real Decreto-Ley 9/2018 de 3 de agosto, de medidas urgentes para el desarrollo del Pacto de Estado contra la Violencia de Género, son municipales.

\subsection{Marketing y género}

Como hemos visto en el apartado anterior, hace ya décadas que la mujer es considerada sujeto especialmente protegible en el ámbito publicitario. Pero más allá de esta cuestión, la variable género ha sido un elemento crucial en el desarrollo de estrategias de marketing desde los inicios de la publicidad moderna. El denominado «marketing de género» parte de la necesidad de implementar e identificar las diferentes necesidades de los hombres y las mujeres en el desarrollo, distribución, fijación de precios y comunicación de productos y servicios (Dema, 2007). Por extensión, se establece un comportamiento de consumo diferenciado entre hombres y mujeres basado en conceptos sociológicos y psicológicos (Velandia y Rozo, 2009).

Sin embargo, esta perspectiva supone abordar el desarrollo estratégico desde dos puntos de vista no exentos de polémica: por una parte se sustenta en la existencia de diferencias importantes entre los géneros a la hora de realizar el consumo y, por otra, apela a la generalización, homogeneización de esas diferencias creando estereotipos. Analizamos dichas cuestiones a continuación.

\subsubsection{Utilización del género en el planteamiento estratégico de las campañas}

Es común que el marketing realice generalizaciones sobre grupos de personas buscando identificar segmentos para conseguir un proceso comercial y una comunicación más efectiva.
Pero estas generalizaciones pueden suponer un problema al referirse a hombres y mujeres ya que la línea entre lo apropiado o no a la hora de realizarlas resulta bastante difusa (Marketing Directo, 2011). Existe una realidad demográfica relativa a las propias tendencias de consumo. De esta forma, los responsables de marketing toman como referencia los datos de compra para establecer sus públicos objetivos: los hombres son los que compran coches, las mujeres son las que compran productos de limpieza, etc. (Lancellotti y Thomas, 2018) De hecho, género y edad siguen siendo los elementos fundamentales a la hora de acotar el público objetivo de la campaña (Ramos y Papí, 2012). Aunque esto pueda resultar cuestionable, el problema se centra especialmente en los elementos empleados para dirigirse a estos segmentos de público. La segmentación por género, que es básica en el desarrollo de una estrategia publicitaria, no debería suponer que los anuncios fueran sexistas (Valls-Fernández y Martínez-Vicente, 2007). Los anunciantes tan sólo pretenden entender las características de sus potenciales clientes para tener éxito, pero también necesitan evitar las generalizaciones extremas que puedan entenderse como sexistas (Báez et al., 2017).

A este respecto, y atendiendo a la subordinación de estrategias (Pérez, 1998), podemos tomar como referencia la estrategias aplicadas en productos específicos para hombres o mujeres. Ese es el caso de la línea de cosmética masculina de L'Oreal que en 2011 utilizaba al actor Hugh Laurie como prescriptor. El mensaje se centraba en «tener buena cara» en la madurez, no se manejaban los conceptos «anti-edad», «rejuvenecimiento» o «antiarrugas» habituales en las de la publicidad de cosmética femenina (Ringrow, 2016). En lo relativo a productos específicamente femeninos, la publicidad de productos de higiene 
femenina lleva años en el ojo del huracán (Ballester, 2015).

En este punto, existe una necesidad clara de aplicar la perspectiva de género al proceso publicitario (De Moreno, 2007), elemento que no tendría que ser contrario a la realización de segmentación de público si no que contribuiría a que esta pudiera realizarse evitando estereotipos y frenando los errores como los que hemos analizado en los apartados anteriores.

\subsubsection{Los estereotipos como recurso de marketing}

«Los estereotipos crean un horizonte de expectativas reconocibles por la ciudadanía, asientan unos valores más o menos inmutables y explican las cosas de una forma harto maniquea: la conversión de la realidad a estereotipos implica la negación de la misma realidad, el dominio de los prejuicios para catalogar las cosas (economía cognitiva), la sustitución del mundo por un mundo alternativo facturado por los medios para que las cosas funcionen de forma previsible» (De Santiago, 2005: 44).

La existencia de estos estereotipos es una realidad desde los primeros tiempos de la publicidad. El Colexio Profesional de Xornalistas de Galicia (2008) publicó un informe en el que indicaba que el 81 \% de los anuncios sexistas en la Televisión de Galicia lo eran por estereotipos de género; 10 años después las cifras parecen no haber variado tanto. Los estudios realizados sobre la actividad publicitaria de la última década han permitido determinar varias líneas fundamentales en las que se concentran los estereotipos relativos a la mujer (Piñeiro-Otero y Costa-Sánchez, 2003; García y García, 2004; López, García y Lajo, 2006) que suponen una mayor gravedad y riesgo social al pasar más desapercibidos que la evidente «cosificación» de años anteriores. Todos ellos siguen vigentes y se repiten sistemáticamente en los casos recogidos desde 2008, por lo que hemos podido establecer una propuesta de categorización. La categorías a, f y g resultan más evidentes para el público en general contando con denuncias al respecto mientras que, las restantes, parecen pasar más desapercibidas para el público y las asociaciones.

\section{a) División sexual del trabajo}

Es quizá el más abundante en el histórico de casos pero, al mismo tiempo es que más parece haberse frenado. Se trata de la representación de la mujer como «ama de casa» y responsable exclusiva del cuidado y educación de los descendientes. La campaña de 2013 de atún Calvo «Ellas lo saben todo» recibió una recomendación por parte del Observatorio de la Imagen de la Mujer ya que «a pesar de que de la campaña se desprende la intención de reconocer la figura materna, se reproducen estereotipos sobre sus roles domésticos, la mujer ejerce el poder absoluto mientras que el padre adopta un papel secundario» (Observatorio, 2013).

La última con este tipo de contenido que localizamos en la base de datos de campañas denunciadas es la del banco Laboral Kutxa que fue requerida para su cese por el Observatorio en 2014. Se trataba de una campaña de publicidad exterior que ofrecía regalos de bandejas de horno para mujeres, recurriendo a estereotipos domésticos. Debemos incidir en que esta marca también tuvo problemas a nivel autonómico (ya en 2017) al estar incluida en las recomendaciones del Área de Defensa de los derechos de Igualdad de Mujeres y Hombres Emakunde del Instituto Vasco de la Mujer, donde se indica que sus anuncios incumplen el Decálogo de Publicidad (Instituto Vasco de la Mujer, 2017) (Imagen 8).

Además de este aspecto, también existe un estereotipo complejo en cuanto al desempeño 


\section{Imagen 8 • Campaña Kutxa Bank (2017)}

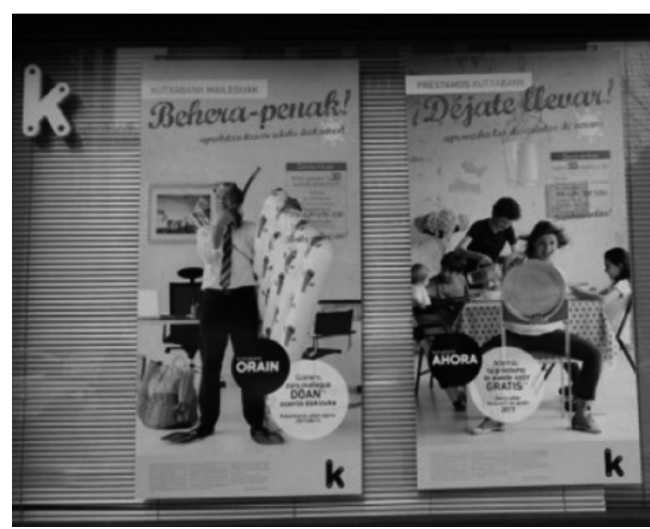

laboral de las mujeres. De esta forma se considera la existencia de profesiones «femeninas» con un menor nivel de responsabilidad que las profesiones consideradas «masculinas» (O’Driscoll, 2018). De esta forma se habla de médicos y de enfermeras, de abogados y secretarias, etc. Este hecho no cuenta con denuncias al tratarse de un planteamiento más sutil, pero sigue siendo común en la publicidad actual. Debemos destacar la polémica desatada en 2018 con los datos aportados por el Sindicato de Enfermería «Satse» que, tras un estudio sobre la situación de la profesión, puso en marcha una campaña titulada «Rompe con los estereotipos» (Imagen 9). El sindicato denunciaba la difusión de imágenes y mensajes que atentaban contra la dignidad de las enfermeras

\section{Imagen 9 • Campaña Satse (2018)}

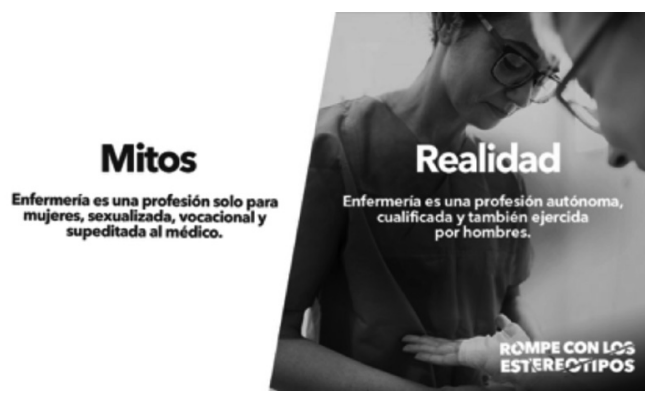

como profesionales y como mujeres y como ha ido en aumento «mostrando una imagen de la enfermería sexualizada y estereotipada» (Tribuna Feminista, 2018).

\section{b) Cuerpo femenino como espacio problemático}

Otro estereotipo común es el referido a que los problemas físicos socialmente más reprobables son cuestión exclusiva de las mujeres. Ellas deben ser las protagonistas de los anuncios de laxantes, anti hemorroides, medicamentos para enfermedades venéreas, etc. Dulcolaxo ha realizado hasta veinte campañas distintas desde el año 2008 en televisión y todas ellas han sido exclusivamente protagonizadas por mujeres; la marca Raylex puso en marcha una campaña (también en televisión) muy agresiva en la que la mujer sufre la consecuencia de su mala costumbre de comerse las uñas. Como ya hemos indicado este planteamiento no fue visto como un problema y, de hecho, la campaña recibió un premio Aspid $^{* * *}$ en 2017. El aumento de la inversión del sector salud en publicidad en los últimos años ha hecho más patente esta realidad, pero no se consideran contenidos denunciables.

En este apartado englobaríamos todas las campañas que centran su mensaje en responsabilizar a la mujer de cuidar su cuerpo conforme a unos estándares de belleza determinados que difícilmente son puestos en cuestión (Taylor, Johnston y Whitehead, 2016). Bien es cierto que, en este caso, el problema estaría en la realidad del propio productos anunciado (adelgazantes, productos de belleza, clínicas de estética o depilación...) pero los estudios realizados al respecto inciden en que lo más grave es la argumentación realizada de tal forma que su consumo o empleo resulte una obli-

*** Premios Aspid de Creatividad y Comunicación Iberoamericana en Salud y Farmacia. 
gación y se elimine la capacidad de decisión sobre su propio cuerpo. Tal es el caso de la campaña de Lipograsil de 2017 (Imagen 10) donde se da por sentado que después de las navidades «hay que ponerse a dieta». En este caso sí se producen denuncias por estas circunstancias. En 2016 fue la marca cosmética Olay quien recibió recomendaciones del Observatorio al indicar la belleza como «la mejor versión de las mujeres».

\section{Imagen 10 · Campaña Lipograsil (2014)}

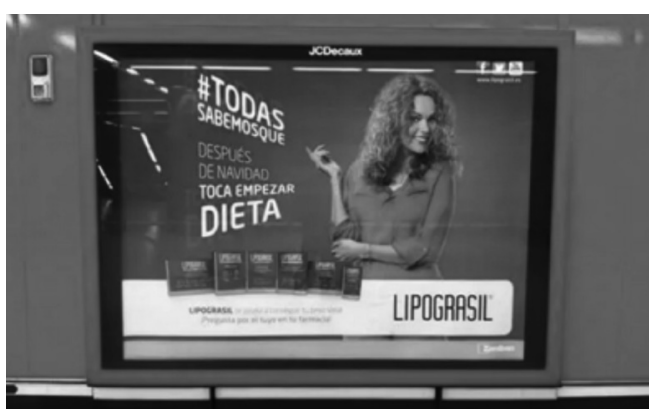

\section{c) Presentación del sexo débil}

Vinculado con lo anterior, las mujeres también son las que necesitan ayuda, las que requieren suplementos vitamínicos, relajantes o pastillas para dormir. En este caso, las campañas del analizadas parecen haber intentado solventar esta cuestión con un recurso que analizaremos más adelante: realizar dos versiones del anuncio, una protagonizada por una mujer y otra por el hombre (es el caso de Dormidina en 2016). Pero esa presentación como sexo débil guarda relación con la «cosificación» de la mujer que parecía haberse limitado en los últimos años.

La utilización del cuerpo de la mujer como elemento simplemente «decorativo» en publicidad resulta agresiva para los consumidores y su uso es rápidamente denunciado, por lo que todo apunta a que las marcas son más cuidadosas (incluso Media Markt a cambiado el tono de su mensaje después de varias denuncias - Imagen 11) siendo

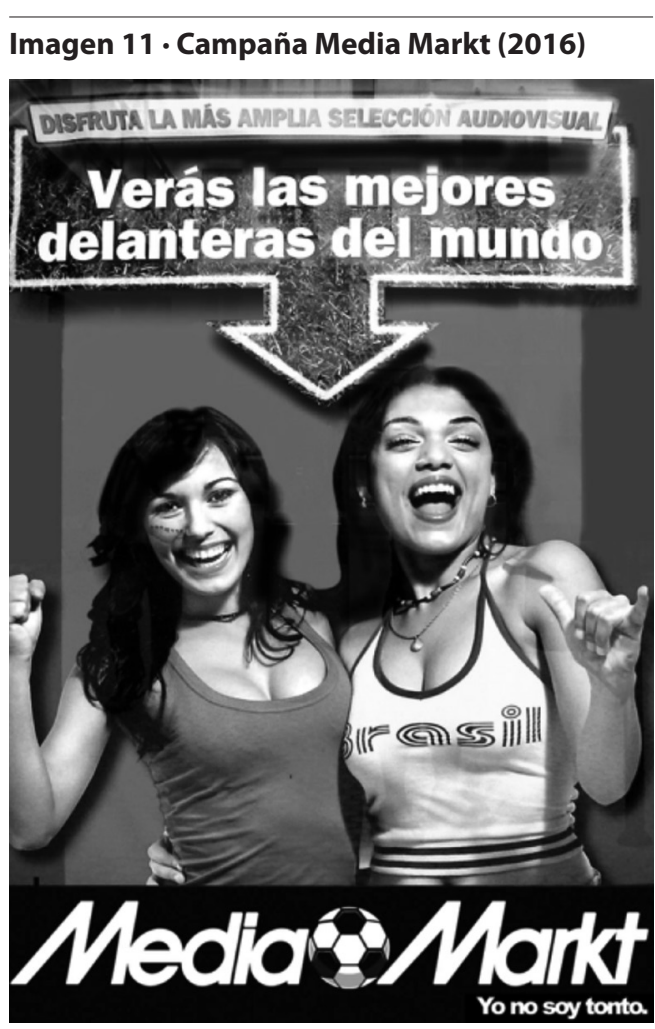

los casos recogidos referidos a marcas menores y, por lo tanto, con una menor difusión. En el caso del Observatorio, el último caso recogido data de 2016, siendo un cartel de una concentración de motos de carácter local (Imagen 12),

Imagen 12 · Cartel concentración de motos (2016)

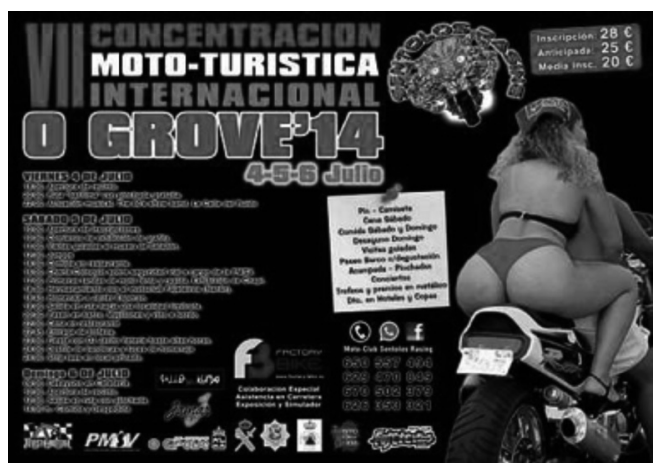




\section{Imagen 13 - Cartel Gimnasio Hammer (2019)}

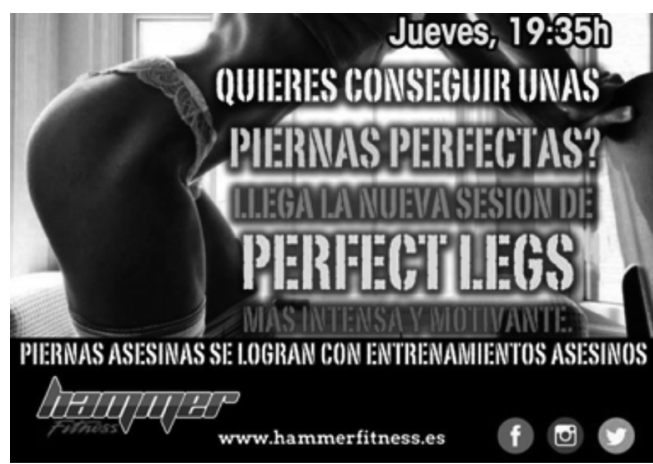

y apareciendo como recurrentes los casos referidos a salas de fiestas, discotecas o gimnasios. La Federación de Asociaciones de Consumidores (Facua) creó, en 2010, el Premio al Peor (y más machista) Anuncio del año, atendiendo a las votaciones de los propios consumidores. En el año 2019 el ganador fue el anuncio de un gimnasio de Sevilla (Imagen 13).

\section{d) Responsable exclusiva del cuidado de los otros}

La mujer es la responsable de que los niños coman (Pediasure, Imagen 14), de que los mayores se cuiden (Meritene, Imagen 15) y de que la pareja mantenga su salud. Todo ello realizado con comprensión, docilidad y asumiendo la responsabilidad en exclusiva de estas cuestiones, mostrando además que es la vía de realización y satisfacción personal de la mujer. En 2016 la

\section{Imagen 14 · Campaña Pediasure (2016)}

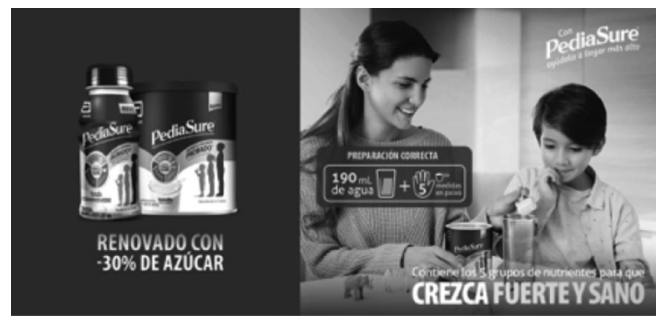

\section{Imagen 15 - Campaña Meritene (2016)}

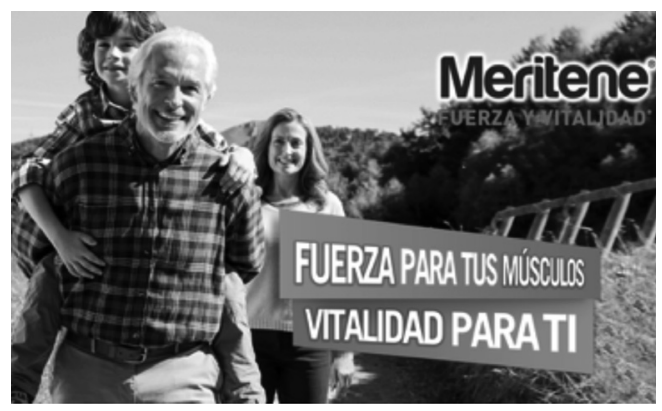

Imagen 16 - Campaña Ikea (2018)

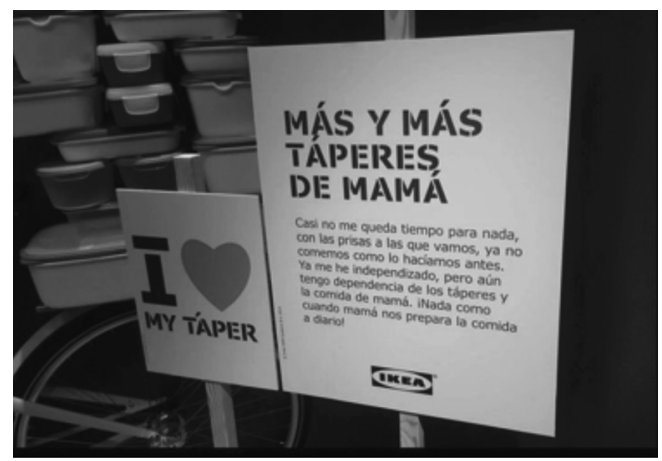

marca Ikea recibió numerosas críticas por una campaña en la que se hablaba de «los tuppers de mamá» (Imagen 16) que fue denunciada por Facua. No podemos perder de vista, una vez más, que ni siquiera es necesaria una representación directa de la mujer para que las campañas incurran en problemas, ya que es el contenido (sutil) de los mensajes, el que esconde sexismo.

\section{e) Limitación del acceso a los espacios de} poder masculino

La mujer es responsable de una parte muy concreta en el hogar, pero las decisiones sobre la gestión y economía son responsabilidad masculina. Así, los hombres son protagonistas mayoritarios de las empresas de telecomunicaciones o energía. De igual forma, los hombres están legitimados para contar con espacios propios de ocio y desarrollo 


\section{Imagen 17 · Campaña Amstel 1(2012)}

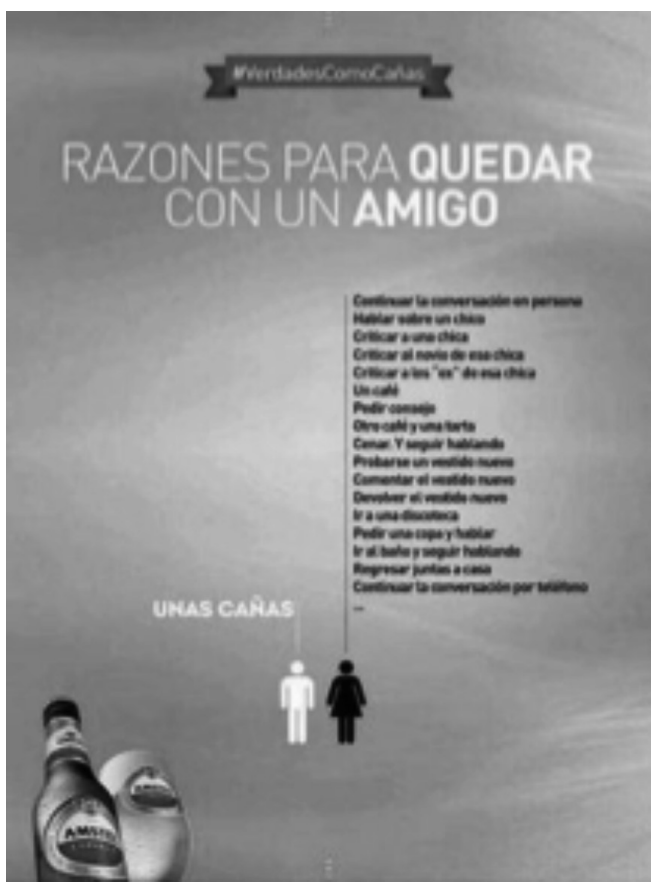

Imagen 18 • Campaña Amstel 2 (2012)

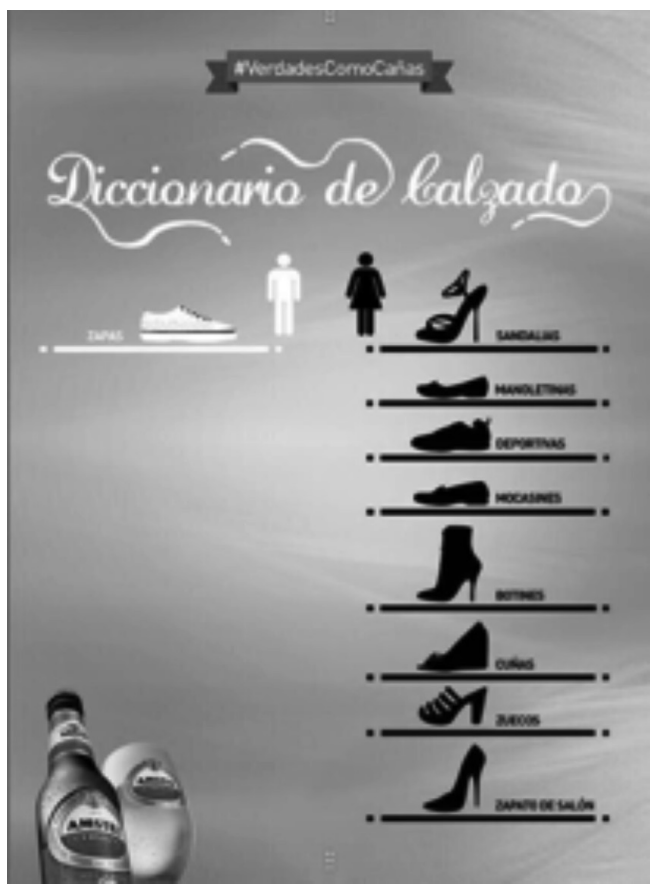

\section{Imagen 19 • Campaña Amstel 3 (2012)}

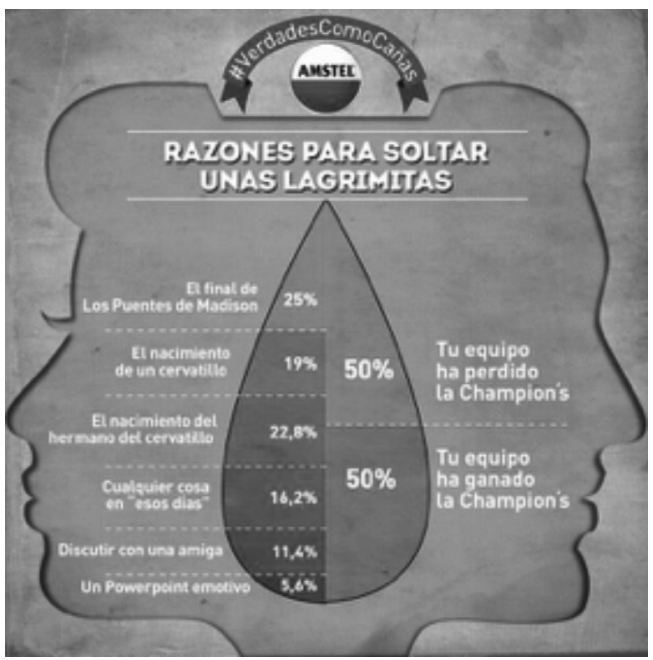

personal, como sucede en lo relativo a marcas de cerveza, donde la mujer sigue sin tener una presencia igualitaria, o en lo referido venta de tecnología. Estos espacios no sólo son excluyentes para la mujer si no que inciden notablemente en marcar la diferencia de la forma más clara posible. En 2014 la campaña de Amstel para redes sociales se convirtió en un ejemplo de esta categoría al publicar varias versiones de un anuncio que tenía como eje «verdades como cañas» y en el que las diferencias hombre y mujer intentaban plantearse con humor (Imágenes 17, 18 y 19) recogían roles sexistas y negativos.

\section{f) Hombre como experto}

En relación a los roles antes expresados, las cuestiones técnicas habitualmente son avaladas por expertos masculinos, especialmente de carácter médico, tal es el caso de las campañas de Sensodyne (Imagen 20). Esto permite que el hombre se integre en los espacios «femeninos» para dar consejos sobre limpieza, cuidado de los niños o la cocina. El papel de «Don Limpio» como revisor de la limpieza que la mujer realizaba 


\section{Imagen 20 - Campaña Sensodyne (2019)}

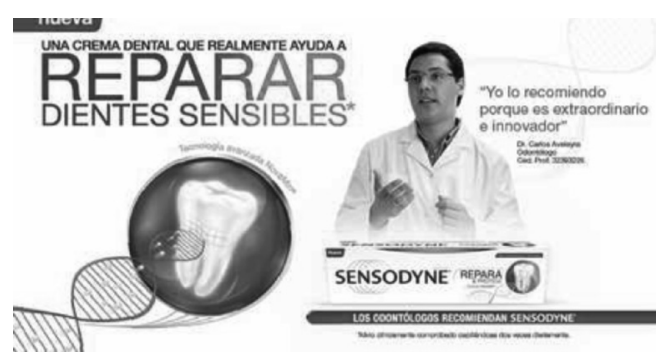

Imagen 21 • Campaña Don Limpio (2014)

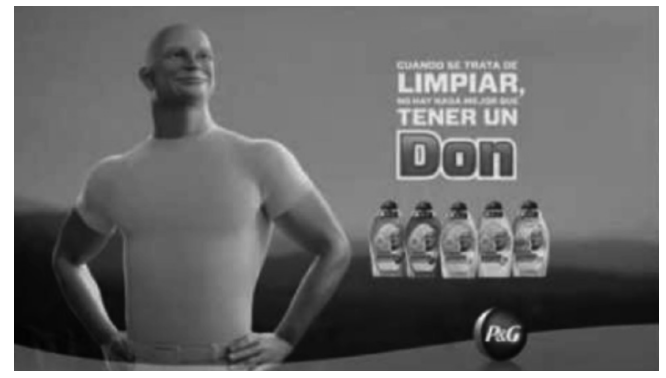

Imagen 22 - Mcdonald's (2016)

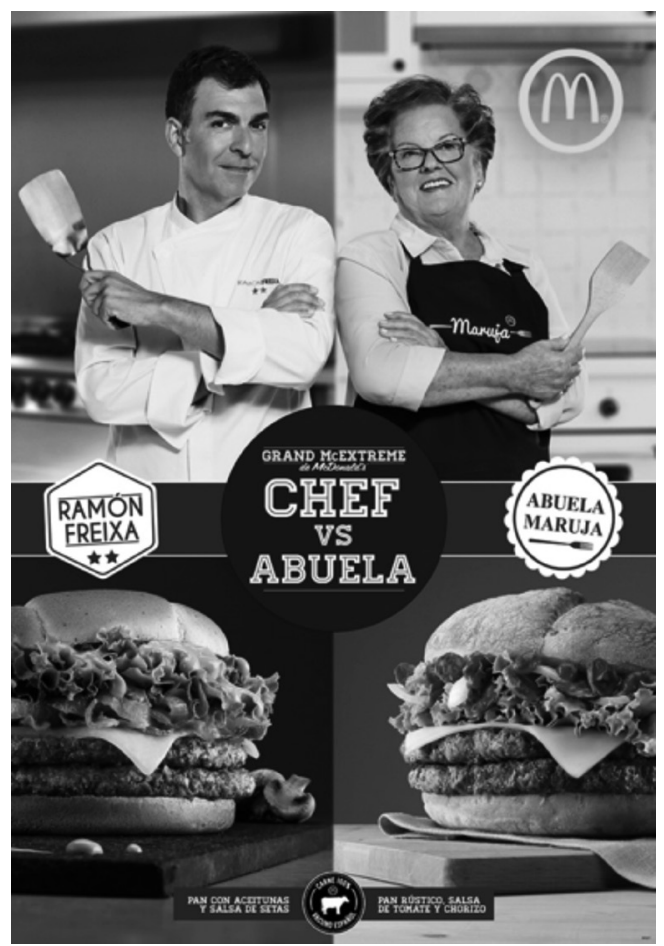

de la casa durante décadas, sigue estando presente a pesar del intento de cambio de rol de este personaje acometido en 2014 y que se prolongó a 2016 (Imagen 21).

Entre los casos más llamativos está la continua colocación de hombres como expertos en cocina estableciendo una diferenciación entre mujeres como amas de casa y hombres como chefs o cocineros de prestigio. En 2016 McDonald’s representó gráficamente esta realizada en una campaña en la que enfrentaba al «Chef» y la «Abuela» (Imagen 22).

\section{g) Mujer como elemento molesto}

A esta clasificación debemos añadir el rol de la mujer como elemento molesto en el ciclo vital del hombre. Ha sido una nueva vía de desigualdad que ha cobrado fuerza en los últimos años, con denuncias recogidas (Imagen 23). Una vez más, justificado como un recurso de humor, los estereotipos sobre la mujer son remarcados. La asociación Ecologistas en Acción otorga, desde 2008, los Premios Sombra a los peores anuncios del año «por transmitir valores sexistas, xenófobos,

\section{Imagen 23 - Campaña Diagonal (2018)}
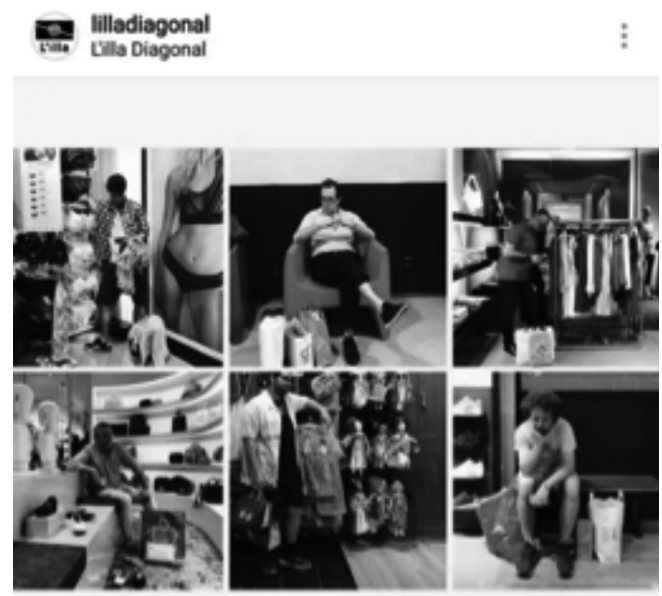

REBAIXES 


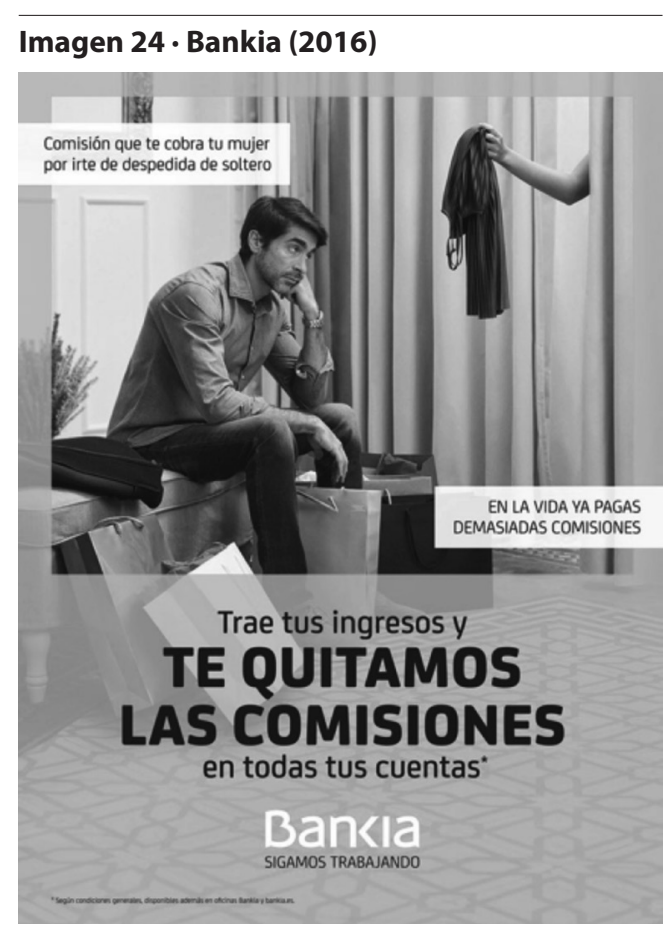

insolidarios, consumistas o por hacer pasar un producto como ecológico sin serlo» (Ecologistas en Acción, 2019). En el año 2016 el finalista en la «Categoría Florero» de este galardón fue Bankia por el anuncio «En la vida ya pagas demasiadas comisiones» (Imagen 24). Según se describe en la presentación de los premios "se trata de un conjunto de historias en las que aparecen parejas «pagando deudas». La forma de contraer las deudas por parte de los hombres banaliza su falta de implicación en las tareas de cuidados y, en concreto, en el cuidado de la relación de pareja. Al mismo tiempo, se favorece una imagen de la mujer excesivamente preocupada (...) por el mantenimiento de la dependencia y la falta de la libertada de la pareja".

\section{Resultados}

Ante la compleja y problemática aplicación del marketing de género y la existencia de los es- tereotipos en torno a la mujer, la publicidad se encuentra en un momento en el que, siendo conscientes de la necesidad de corregir esos vicios, puede no estar realizando adecuadamente la aplicación de la perspectiva de género. Todos los casos recogidos demuestran una amplísima variedad de casuísticas a las que hay que hacer frente e incluso una evolución de los mensajes que «edulcoran» los conceptos más sexistas o discriminatorios, pero siguen transmitiendo una imagen negativa del sexo femenino. Pero no sólo podemos quedarnos con la cuestiones negativas, si no que se trata de identificar conductas positivas que pueden (o no) ser adecuadas para contrarrestar los problemas de género existentes en la publicidad. Del análisis realizado se extraen dos vías de trabajo básicas:

a) Equiparación. Se han realizado esfuerzos para que el hombre ocupe los mismos espacios de la mujer (no al contrario). De esta forma es ya habitual observar hombres encargándose del cuidado de la casa y de los niños, pero no es un proceso que resuelva completamente el problema. Una vez más la mujer es la observadora y la responsable final de estas cuestiones, comprobando como realiza las tareas el varón y en cuanto al desempeño masculino, parece normal expresar este como torpe y poco ducho en esas actividades. Un ejemplo paradigmático es el de Direct Seguros «Padres Responsables» (Imagen 25) en el que es la mujer la que supervisa desde el retrovisor como el hombre coloca a los niños en el asiento trasero del coche.

Como hemos indicado, esta equiparación supone que el hombre ocupe espacios y roles hasta ahora considerados femeninos, con lo cual nos encontramos con casos en que la «cosificación» femenina se ha trasladado al varón (Drake, 2016). Así, la exhibición injustificada o parcial de cuerpo 


\section{Imagen 25 - Campaña Direct Seguros (2016)}

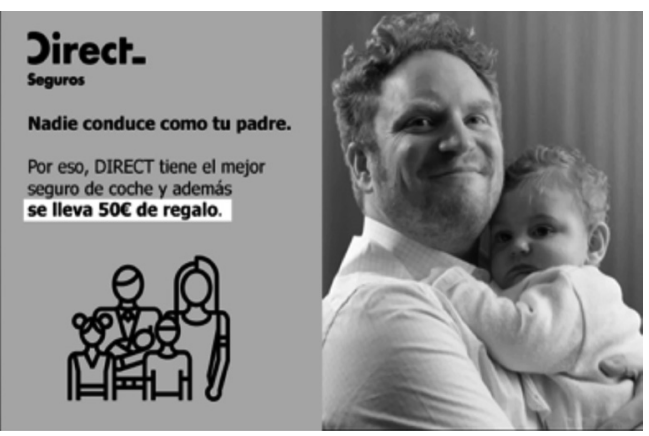

masculino ha cobrado especial fuerza. En este sentido, queda claro que la solución no parece encontrarse en que el mismo uso inadecuado que se realizaba de este recurso se aplique ahora al hombre. Un ejemplo claro es la campaña de Dolce Gabbana, que tras la denuncia recogida en su campaña de 2008 (Imagen 2) respondió con campañas como la publicada en 2016 (Imagen 26). Obviamente este recurso ha suscitado un profundo debate, tanto por el uso visual del cuerpo masculino como por el planteamiento de roles comunes a ambos sexos. La campaña publicada por el Gobierno de La Rioja en 2018 con el gallo del Día de la Mujer fue denunciada ante el ente autonómico responsable por esta circunstancia (Imagen 27).

\section{Imagen 26 - Campaña Dolce Gabbana (2016)}

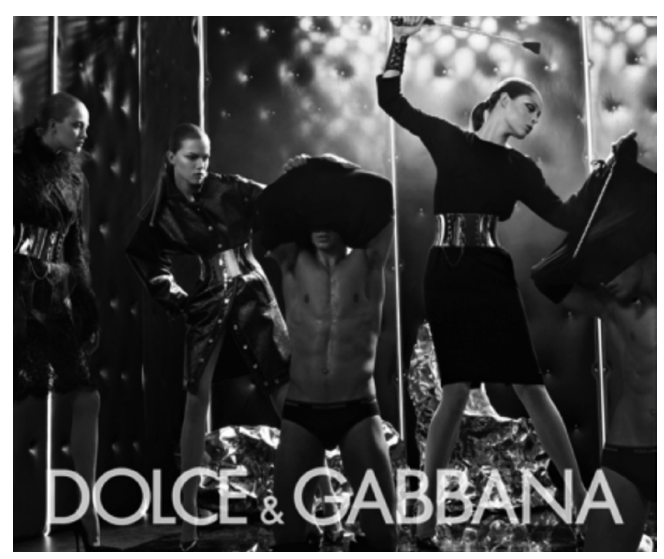

\section{Imagen 27 - Campaña Gobierno de La Rioja} (2018)

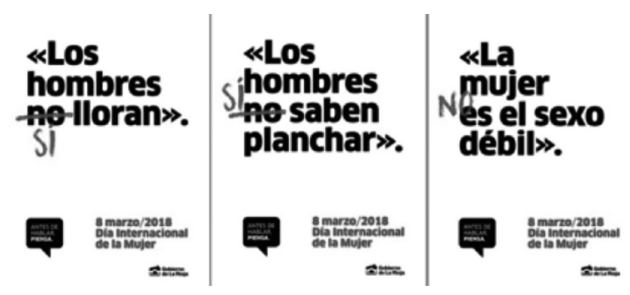

b) Compensación. Otra vía recurrente para evitar la problemática relativa al género en la publicidad es la compensación mediante la aplicación de los dos ángulos. De esta forma, el spot de Westwing (2016) en el que un hombre propone «devolver» a su pareja empaquetándola literalmente, cuenta con una versión masculina del mismo concepto donde el empaquetado es el chico. Se trata de una solución que puede ser discutida, sin duda. Esto es lo que sucedió con la campaña de perfume One Million de Paco Rabanne, pero que no evitó que la campaña recibiera quejas al respecto por los matices existentes entre la versión masculina y femenina (Observatorio, 2013). También podemos mencionar como Finish intentó frenar las continuas críticas por su representación de la mujer como responsable de la limpieza con las dos versiones del anuncio (Imágenes 28 y 29).

Como no puede ser de otra forma, una vez identificados los problemas y las potenciales soluciones aportadas por las marcas, la cuestión se centra en poder valorar las causas de que esas líneas de uso y abuso de la imagen de la mujer sigan presentes (Akestam, Rosengren y Dahlen, 2017) y sin posibilidad real de erradicarse, pero podemos recoger lo aportado por Grow, Roca y Broyles (2012) cuando indicaban, con respecto a España, que el problema radica en la propia realidad de las agencias publicitarias, donde la mujer sigue estando menos presente. De esta 


\section{Imágenes 28 y 29 • Campaña Finish (2016)}

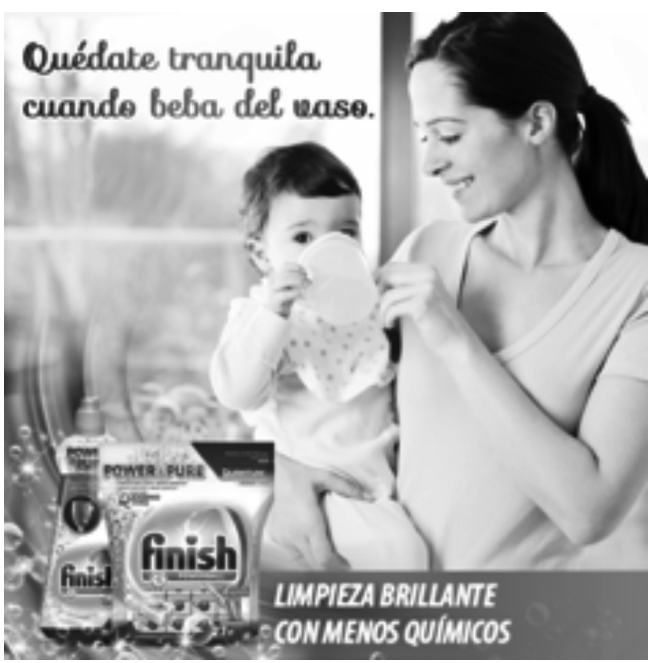

forma, indican varios parámetros que determina esa ausencia:

«1) La selección final de las ideas es hecha por hombres, 2) las mujeres son más democráticas a la hora de encontrar soluciones, 3) en las presentaciones ante el cliente las mujeres se sienten marginadas, 4) los productos se asignan según el género (productos femeninos vs. productos masculinos), 5) las cuentas (clientes) con más posibilidades de ganar premios se asignan a hombres, 6) las mujeres dejan la profesión para buscar trabajos con menos estrés, para evitar un entorno altamente masculinizado que las perjudica y, cuando son madres, para ganar la flexibilidad».

\section{Conclusiones}

La complejidad del análisis de nuestro objeto de estudio radica en la amplitud de matices y consideraciones que pueden realizarse al respecto. La gravedad del problema no está tan sólo en los referidos estereotipos si no que, incluso en el momento actual, el lenguaje sexista y la agresión contra la dignidad femenina sigue estando pa-

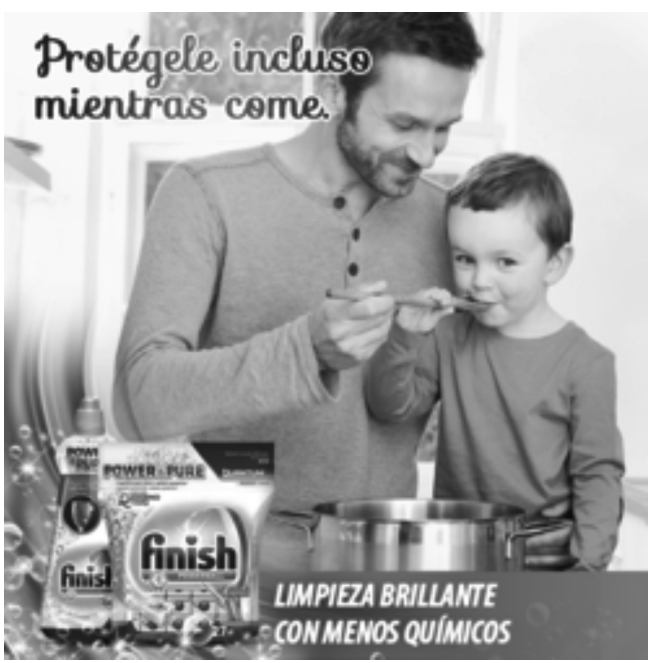

tente. Bien es cierto que las grandes compañías suelen ser más cuidadosas al respecto ya que existe una presión social clara al respecto. Sin embargo siguen produciéndose casos siendo estos más habituales en la publicidad con difusión más limitada (folletos, flyers, publicidad en prensa...).

La agresión contra la dignidad femenina tiene mucho que ver con el uso que se hace de la imagen y el cuerpo de la mujer. La asociación de la imagen de la mujer para la venta de productos considerados masculinos, como simple adorno o complemento sigue siendo frecuente y socialmente asumida en algunos casos. En lo relativo al cuerpo femenino, el problema no está en la desnudez del mismo si no en la descontexualización, fragmentación e incluso «cosificación», que han llegado a general incluso una mala imagen para la propia publicidad como disciplina (Huhmann y Limbu, 2016).

En lo relativo a las consecuencias, ha quedado claro que sí existe una preocupación social por este aspecto y es, precisamente, la presión social la que consigue más soluciones que la propia limitación normativa. Desde el punto de vista socio- 
lógico el aspecto que, en lo relativo al marketing y la comunicación, sin duda, más preocupación debería suscitar es el relativo a la configuración de la imagen del género femenino, donde la mujer se encuentra avocada a desempeñar lo que se denomina «tercera jornada laboral». De esta forma la mujer debe desempeñar su jornada laboral en su puesto de trabajo, otra jornada laboral responsabilizándose del hogar y una tercera en lo relativo al cuidado de su físico.

La existencia de limitaciones normativas en lo relativo a la publicidad no parece ser suficiente para evitar los abusos que se producen en lo relativo a la imagen de la mujer. Los distintos esfuerzos realizados tanto desde el propio sector (Autocontrol) como de las instituciones públicas han conseguido pequeñas y costosas victorias que se traducen en la concienciación sobre la existencia de un problema. A pesar de los discretos progresos sigue siendo sencillo localizar ejemplos de malas prácticas, incluso sin apelar a aquellos que han sido objeto de denuncias o reclamaciones.

Siendo conscientes de la importancia de la publicidad en la configuración del imaginario colectivo, es fundamental buscar soluciones a este problema. Todos y cada uno de los casos analizados en este trabajo se circunscriben al periodo entre
2008 y la actualidad y, como hemos indicado, se perciben intentos de mejorar la situación, pero o bien no son suficientes o están errados en su planteamiento. La línea entre la segmentación de los públicos y la creación de estereotipos es muy fina por lo que se debe seguir trabajando en la solución adecuada. El marketing de género no es la cuestión, si no aplicar la perspectiva de género en publicidad.

Se trata de una aportación de gran interés ya que, en los últimos años, se han reducido notablemente los estudios a este respecto y, si bien la perspectiva cuantitativa parece estar cubierta por instituciones como el Observatorio de la Mujer - que presentan datos sobre las campañas denunciadas o retiradas por esta circunstancia no se contemplan valoraciones cualitativas sobre qué tipo de mensajes se están divulgando y, sobre todo, si se está evolucionando y mejorando en este aspecto.

Los resultados de este trabajo tienen implicaciones sociales de gran calado ya que supone poner sobre la mesa problemas de sexismo y maltrato de la imagen de la mujer que estaban pasando desapercibidos o incluso estaban asumidos. Todo esto resulta de gran utilidad, además, para los creadores de campañas de comunicación. 


\section{Bibliografía}

Åkestam, N., Rosengren, S. \& Dahlen, M. (2017). Advertising "like a girl": Toward a better understanding of "femvertising" and its effects. Psychology \& Marketing, 34(8), 795806.

Arconada, M. A. \& Lomas, C. (1999). Mujer y publicidad: de la diferencia a la desigualdad en Lomas, C. (Coord.) ¿Iguales o diferentes?: género, diferencia sexual, lenguaje y educación. Madrid, Paidós Ibérica.

Báez, J. M. et al., (2017). Feminists, Feminisms, and Advertising: Some Restrictions Apply. Lexington Books.

Balaguer Callejón, M. L. (1985). La mujer y los medios de comunicación de masas: el caso de la publicidad en televisión. Málaga, Arguval.

Balaguer, M. L. (2008). Género y regulación de la publicidad en el ordenamiento jurídico. La imagen de la mujer. Revista Latina de Comunicación Social, 63, 382.

Ballester, V. (2015). La representación de la menstruación en la publicidad asociada al producto. Análisis de Evax (1996) y Ausonia (Tampax Pearl, 2013). Trabajo de Fin de Grado. Universidad Jaume I. 26 de junio de 2015. Disponible en: https://cutt.ly/qrsAlq9

Berganza, M.R. \& Del Hoyo, M. (2011). La mujer y el hombre en la publicidad televisiva: imágenes y estereotipos. Zer. Revista de estudios de comunicación, 21 (11).

Colexio Profesional de Xornalistas de Galicia (2008). Informe sobre o sexismo na publicidade dos medios de comunicación de Galicia. Santiago de Compostela: Xunta de Galicia. Disponible en: http://igualdade.xunta.es/sites/default/files/ files/documentos/infsexcom_0.pdf

Craig, R. S. (1992). The effect of television day part on gender portrayals in television commercials: A content analysis. Sex roles, 26(5-6), 197-211.

De Moreno, S. (2007). La introducción de la perspectiva de género en el marketing. Una nueva forma de analizar las relaciones de intercambio. Estudios sobre Consumo, 81, 55-69.

De Santiago, J. (2005). Principios de comunicación persuasiva. Madrid, Arco Libros.

Del Moral, M. E. (2000). Los nuevos modelos de mujer o de hombre a través de la publicidad. Comunicar: Revista cientifica iberoamericana de comunicación y educación, (14), 208-217.
Dema, S. (2007). La introducción de la perspectiva de género en el marketing: Una nueva forma de analizar las relaciones de intercambio. Estudios sobre consumo, 81, 55-69.

Diario Oficial de las Comunidades Europeas del 10 de noviembre de 1995, n C296/15.

Drake, V. E. (2017). The impact of female empowerment in advertising (femvertising). Journal of Research in Marketing, 7(3), 593-599.

Eisend, M., Dens, N., \& De Pelsmacker, P. (2019). Gender Roles in Advertising. Advertising Theory, 187-197.

Ellemers, N. (2018). Gender stereotypes. Annual review of psychology, 69, 275-298.

García, E. C. \& García, I. (2004). Los estereotipos de la mujer en la publicidad actual. Questiones publicitarias, 9, 43-64.

Grau, S. L. \& Zotos, Y. C. (2016). Gender stereotypes in advertising: a review of current research. International Journal of Advertising, 35(5), 761-770.

Grow, J. Roca, D. \& Sheri, J.B. (2012). Vanishing acts: creative women in Spain and the United States. International Journal of Advertising, (31) 4.

Huhmann, B. A. \& Limbu, Y. B. (2016). Influence of gender stereotypes on advertising offensiveness and attitude toward advertising in general. International Journal of Advertising, 35(5), 846-863.

Ibarra, A. (2001). La investigación en comunicación masiva y comportamiento social: una visión de su historia y concepción. Comunicación y Sociedad, 40.

Lancellotti, M. P. \& Thomas, S. (2018). Men hate it, women love it: Guilty pleasure advertising messages. Journal of Business Research, 85, 271-280.

López, E., García, M. \& Lajo, R. (2006). Las imágenes de las mujeres en la publicidad: estereotipos y sesgos. Redes. Com-Revista de Estudios para el desarrollo social de la comunicación, 3, 77-90.

Marketing Directo (2011). La segmentación por género ¿sexismo o marketing?, Marketing Directo, 9 de febrero de 2011. http://www.marketingdirecto.com/actualidad/publicidad/la-segmentacion-por-genero-\%C2\%BFsexismo-omarketing/

Martínez, E. \& Nicolás, M.A. (2019). Panorámica de las reclamaciones en publicidad y menores en Autocontrol (1998-2018). Comunicación y Hombre. 15, 163-176. 
Montero, M. (2011). Mujer, publicidad y consumo en España. Una aproximación diacrónica. Anagramas: Rumbos y sentidos de la comunicación, 9(18), 83-92.

Naciones Unidas (2000) Nota informativa $n^{\circ} 10$, La mujer y los medios de comunicación, Período extraordinario de sesiones de la Asamblea General de las Naciones Unidas, La mujer en el año 2000: igualdad entre géneros, desarrollo y paz en el siglo XXI, Nueva York, 9 de junio.

Navarro-Beltrá, M. \& Martí Llaguno, M. (2012). La publicidad sexista en España: eficacia de la Ley Orgánica de Medidas de Protección Integral contra la Violencia de Género. Cuestiones de género: de la igualdad y la diferencia, 7, 247-267.

O'Driscoll, A. (2018). Learning to Sell Sex (ism): Advertising Students and Gender. Nueva York: Springer.

Peña-Marín, C. \& Frabetti, C. (1990). La mujer en la publicidad. Madrid: Instituto de la Mujer.

Perelló, S., Muela, C. \& Hormigos, J. (2016). Publicidad ilícita, productos saludables y autorregulación. Cuadernos. info, (38), 51-67.

Pérez, R. A. (1989). Estrategia de la Comunicación Publicitaria y de las Relaciones Públicas. Madrid, Universidad Complutense de Madrid.

Piñeiro-Otero, T. \& Costa-Sánchez, C. (2003). Representaciones femeninas en la publicidad. Una propuesta de clasificación. Revista de la SEECI, 6(10), 1-13.

Ramos Soler, I. \& Papí Gálvez, N. (2012). Personas mayores y publicidad: representaciones de género en televisión. Estudios sobre el Mensaje Periodístico, 18, 753-762.

Ringrow, H. (2016). The Language of cosmetics advertising. Nueva York: Springer.
Ruiz Vidales, P. \& Muñiz, C. (2017). Estereotipación de la mujer en la publicidad política. Análisis de los estereotipos de género presentes en los spots electorales de la campaña 2015 en Nuevo León. Comunicación y sociedad, 29, 69-91.

Sahui, J.; Pérez, C.A. \& Vargas, M.A. (2015). Influencia de los medios de comunicación y de la publicidad en el consumo: una aproximación crítica. PAG. Revista Iberoamericana de Producción Académica y Gestión Educativa, 3, junio-diciembre.

Santiso Sanz, R. (2001). Las mujeres en la publicidad: análisis, legislación y aportaciones para un cambio. Acciones e investigaciones sociales, 13, 43-60.

Santiso, R. (2001) Las mujeres en publicidad: análisis, legislación y aportaciones para un cambio. Acciones e investigaciones sociales, 3, 43-60.

Taylor, J., Johnston, J. \& Whitehead, K. (2016). A corporation in feminist clothing? young women discuss the dove 'Real beauty'campaign. Critical Sociology, 42(1), 123-144.

Tribuna Feminista (2018) «El 35\% de las enfermeras ha recibido comentarios sexuales en la consulta». El Plural, 29 de abril de 2018

Valls-Fernández, F. \& Martínez-Vicente, J. M. (2007). Gender stereotypes in Spanish television commercials. Sex roles, 56(910), 691-699.

Vega, S. M., Barred, D. \& Merchán, A. (2019). Percepción de los comportamientos y patrones corporales asignados a la mujer en publicidad. Ámbitos. Revista Internacional de Comunicación, 44, 162-180.

Velandia, A. \& Rozo, J. (2009). Estereotipos de género, sexismo y su relación con la psicología del consumidor. Psychologia. Avances de la disciplina, 3(1), 17-34. 


\section{Webgrafía}

Imagen 1. Campaña de Ryanair (2012). El País (2012). Disponible en: https://elpais.com/elpais/2011/12/15/mujeres/1323930720_132393.html

Imagen 2. Campaña de Dolce $\mathcal{E}$ Gabbana (2008) Fuente: El Confidencial (2018). Disponible en: https://www.vanitatis. elconfidencial.com/estilo/moda/2018-11-21/dolce-gabbana-racismo-cancelan-desfile-china_1659346/

Imagen 3. Campaña de productos capilares (2017) Fuente: El País (2017) Disponible en: https://elpais.com/ccaa/2017/ 03/31/catalunya/1490961511_188130.html

Imagen 4. Campaña asociación nuestros hijos (2018) Fuente: El País (2018). Disponible en: https://elpais.com/sociedad/2018/11/28/actualidad/1543399710_164371.html

Imagen 5. Campaña Ministerio (2017) Fuente: Ministerio de Sanidad, Servicios Sociales e Igualdad, 2017.

Imagen 6. Campaña Ministerio (2009) Fuente: Ministerio de Sanidad, Servicios Sociales e Igualdad, 2009.

Imagen 7. Campaña Punto Matic (2008) Fuente: IPMark, 2008

Imagen 8. Campaña Kutxa Bank (2017) Fuente: Instituto Vasco de la Mujer (2017).

Imagen 9. Campaña Satse (2018) Fuente: Sindicato SATSE (2018)

Imagen 10. Campaña Lipograsil (2014) Fuente: Observatorio de la imagen de la mujer (2019).

Imagen 11. Campaña Media Markt (2016) Fuente: Observatorio de la imagen de la mujer (2012).

Imagen 12. Cartel concentración de mo+tos (2016) Fuente: La Voz de Galicia (2016). Disponible en: https://www.lavozdegalicia.es/noticia/pontevedra/2014/05/26/polemico-cartelcertamen-motos-grove-sera-redisenado/0003_2014 05P26C3991.htm

Imagen 13. Cartel gimnasio Hammer (2019). Fuente: Facua (2019).
Imagen 14. Campaña Pediasure (2016) Fuente: Pediasure (2019)

Imagen 15. Campaña Meritene (2016) Fuente: Meritene (2019).

Imagen 16. Campaña Ikea (2018) Fuente: El Plural. Disponible en: https://www.elplural.com/sociedad/ikea-los-taperes-de-mama-y-otros-anuncios-machistas_86094102

Imágenes 17 y 18. Campañas Amstel (1 y 2), (2012); Fuente: El Confidencial. Disponible en: https://www.elconfidencial. com/alma-corazon-vida/2013-08-29/amstel-loterias-niveapublicidad-al-limite-del-sexismo_22151/

Imagen 19. Campaña Amstel (3), (2012) Fuente: El Confidencial.

Imagen20. Campaña Sensodyne (2019) Fuente: Sensodyne (2019)

Imagen 21. Campaña Don Limpio (2014) Fuente: Youtube (2019). Disponible en: https://www.youtube.com/watch?v= nQVEEoM4tv0

Imagen 22. Campaña Mcdonald's (2016). Fuente: McDonald's (2019)

Imagen 23. Campaña Diagonal (2018) Fuente: El Mundo (2018). Disponible en: https://www.elmundo.es/cataluna/2 018/07/03/5b3b533be5fdea8e2f8b45da.html

Imagen 24. Campaña Bankia (2016) Fuente: El País (2018) Disponible en: https://elpais.com/economia/2017/12/15/publizia/1513334062_180349.html

Imagen 25. Campaña Direct Seguros (2016) Fuente: Direct Seguros (2016).

Imagen 26. Campaña Dolce Gabbana (2016) Fuente: Dolce Gabbana (2019).

Imagen 27. Campaña Gobierno de La Rioja (2018) Fuente: Rioja2 (2018). Disponible en: https://www.rioja2.com/n117852-2-el-gobierno-defiende-firmemente-su-campanadel-dia-de-la-mujer-pero-anuncia-su-retiradal Imágenes 28 y 29. Campaña Finish (2016) Fuente: Finish (2019) 